\title{
Covid-19 Pandemic Impact on Maternal and Child Health Services Access in Nampula, Mozambique: A Mixed Methods Research.
}

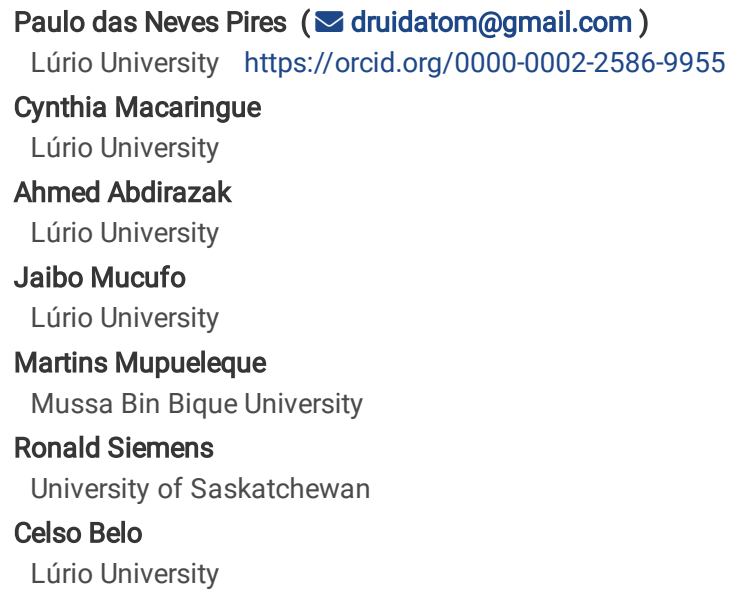




\section{Abstract}

\section{Background}

The Covid-19 pandemic limited access to health services in most countries, impacting negatively global health. Last March 2020 in Mozambique, a public state of emergency restrained people's movements, reduced public services, and launched a national information campaign. The Alert Community for a Prepared Hospital implementation research, has been promoting access to maternal and child health care, at Marrere General Hospital and Marrere Health Centre, in Natikiri, Nampula, the city with the third highest incidence of Covid-19 in Mozambique. Our research aimed to assess the impact of Covid-19 on access to maternal and children health services in Nampula and estimate Alert Community for a Prepared Hospital project sustainability.

\section{Methods}

Mixed-methods research, descriptive, cross-sectional, and retrospective, using review of patient visits documentation, comparing March to May 2019 to same months in 2020, and interviews with health professionals, traditional birth attendants and patients. We involved two health centres and two hospitals. The two Marrere centres were Alert Community for a Prepared Hospital intervention centres, and the other two were control centres, compared using KrushKall Wallis, One-way Anova, mean and standard deviation tests.

\section{Results}

Comparing 2019 maternal health services indicators with those from 2020, the intervention area had decreases of $28 \%$ in family planning visits, $26 \%$ in women in first ante-natal visits in the first trimester, and a $74 \%$ increase in home deliveries, all without statistical significance. The decrease in hospital maternity deliveries $(4 \%)$ was statistically significant $(p=0.046)$. The non-intervention area showed a decrease in women in first ante-natal visits in the first trimester $(12 \%)$. Concerning child health, the intervention area had a $20 \%$ reduction in children presenting for vaccination and an $18 \%$ in children completely vaccinated, comparable to a reduction of $16 \%$ in the non-intervention area. Interviews revealed that most health professionals, traditional birth attendants and patients, have adequate knowledge about Covid-19.

\section{Conclusion}

Our results demonstrate negative collateral effects of Covid-19 on maternal and child health access and a deficient health information system in Mozambique. The Government's media campaign promoting access to preventive health services, is not achieving its aim. The Alert Community project will need further research, to assess lasting effect on reducing the negative effects of Covid-19 on sexual and reproductive health.

\section{Trial registration}

This study was not registered in any data base.

\section{Background}

Covid-19 virus pandemic infected more than 30 million persons in the world (August 2020), ${ }^{1}$ and strongly overcharged national health care services in most countries, ${ }^{2}$ causing indirect outputs like limiting access to and delivery of public and private health care services, ${ }^{3}$ with serious collateral negative effects. ${ }^{4}$

In Mozambique, the President declared the state of emergency in the end of March 2020, when there was no positive cases in the country, limited people movements, reduced all public services and gatherings, launching an information and education national campaign on social media (television and radio) teaching preventive measures. Those preventive measures might have reduced the number of infections: Mozambique is in the 9 th position in the number of cases in Africa (3651), mostly men (60\%), mainly within 25 and 44 years of age (53\%), 58\% asymptomatic and $34 \%$ with light symptoms and 21 deaths (0.6\% death rate, the 7th smallest in Africa). But they have also diminished the number of health professionals (HP) at health centres (primary care) and hospitals (secondary, tertiary and quaternary care); this pandemic collateral output, aggravated by misinformation through social media networks, ${ }^{5}$ decreased the number of users at all health care levels. Consequences on national health programs are not well known. But the negative impacts are documented in a British National Health System research, recommending HP and local authorities, a strong attention to prevent health care access restrictions. ${ }^{6}$

Many women and children in Mozambique faced barriers to access health services, even before the COVID-19 pandemic began, and maternal and child health $(\mathrm{MCH})$ is one of Mozambican government priorities, that has been implementing family planning (FP), ante-natal assistance, maternity delivery, children monitoring and vaccination programs. These target groups have high morbidity and mortality rates, far from the Sustainable Development Goals, and might be now in higher risk with the response to Covid-19. ${ }^{7}$

The Alert Community for a Prepared Hospital implementation research (ACPH), a partnership between the Faculty of Health Science (FHS) of Lúrio University (UniLúrio) with the University of Saskatchewan in Canada, and Nampula Provincial Health Board, is promoting in Natikiri, Nampula, for the last four years, access to maternal, child and adolescent health care, at Marrere General Hospital (MGH) and Marrere Health Centre (MHC). ${ }^{8}$ The base line study' designed strategies, were to empower local communities and leaders, including traditional birth attendants (TBAs), on sexual and reproductive health (SRH), SRH rights and participation in health services, contraceptives and FP, implement a motorcycle ambulance transport system for delivering women, and training HPs on obstetric risk, new-born resuscitation, humanized care, patient centred consultation, family friendly visit and obstetric ultrasonography. ${ }^{9}$

Nampula is the third city in the country (over 663.212 inhabitants), capital of the most populated province (over 6 million) and has the third Covid-19 incidence in the country (517 cases), after Maputo and Cabo Delgado. The number of Covid-19 cases is insignificant when compared to malaria, cholera, tuberculosis, 
human immunodeficiency virus (HIV) infections or road accidents deaths. This made us to evaluate the health units (HU) resilience to the pandemic, to support Ministry of Health (MISAU) decisions on priorities, and to access the sustainability of ACPH interventions to better MCH in Natikiri.

\section{Methods}

The aim of this study was to evaluate the impact of Covid-19 pandemic, on $\mathrm{MCH}$ care services access in Nampula city and estimate ACPH implementation research results sustainability.

This is a mixed-methods explanatory design research, descriptive, cross-sectional, and retrospective, applying documental review (maternal and child health care statistical indicators at HU), comparing March, April, and May 2019 with the same period in 2020. This was then followed by interviews to HP, TBAs and users, respecting COREQ checklist (see additional file).

Quantitative data was obtained from HUs monthly official statistics, at MCH departments. We checked two health centres (Marrere, 25 de Setembro) and two hospitals (Marrere General and Nampula Central) users' tendencies, respectively with and without ACPH project intervention, collecting data during July 2020. Quantitative data was recorded on Microsoft Office Excel, double checked by research assistant and statistics lecture, and analysed by number and percentage. It was then run through SPSS21 to test significant changes in access to MCH services between 2019 and 2020, using Krushkall Wallis, One-way Anova and mean and standard deviation tests, statistically confirmed when $p$-value " $<\mathrm{a}<$ " 0.05 .

ACPH had a data base with phone numbers of TBAs in the Natikiri area. They were interviewed privately by two authors (female Macaringue C. and male Abdirazak A., general practicians, FHC's lecturers, with training and experience in interviewing), with scientific interest in the research topic, unknown and with no relationship with participants prior to study commencement. In collaboration with TBAs, we were able to further contact mothers and pregnant women to interview. HPs were interviewed in their workplace. Subjects were a proposed sample of HPs (nine), TBAs (six in Natikiri) and patients or users (six in Natikiri) of $\mathrm{MCH}$ services. Due to the Presidential declaration of a State of Emergency, in response to the COVID-19 pandemic, community members were interviewed by cell phone and HPs in person respecting preventive measures, during August 2020, each for 30 minutes. The interview model was developed for this study, pretested and provided by the authors, conducted in Portuguese or Emakhuwa (local language), following participant preference, taking notes in the written model. There were no refusals, drop out or repeated interviews.

Conversations were record after participants verbal consent and transcribed to Microsoft Office Word by the same research assistants. Qualitative data was then transferred to NVIVO program for analysis. We used inductive content analysis, targeting four speech categories and ten themes: 1) Knowledge about the disease Covid-19 (cause, symptoms, prevention, social impact); 2) Impact of CoVid-19 in access to HU (population' behaviour, user's behaviour); 3 ) Health system response (HP, MCH); 4) Impact on motorcycle-ambulance usage (demand, service).

\section{Results}

\section{Quantitative results}

Comparing the three months of Covid-19 pandemic in Natikiri, Mozambique in 2020, with the same period in 2019, concerning maternal health services access indicators, data shows increases of domiciliary deliveries (74\%), of the number of pregnant women in the first ante-natal visit and women with four ante-natal visits (19\%), of the number of new-born visits (14\%), and decreases of $26 \%$ in the number of women in first ante-natal visit in the first trimester, and $28 \%$ of elective c-sections, all without statistical significance; a decrease of $4 \%$ on intra-hospital deliveries was statistically significant $(p=0,046$, see Table 1$)$. 
Table 1

maternal health services in intervention area, Natikiri, 2019-2020.

\begin{tabular}{|c|c|c|c|c|c|c|c|c|c|c|c|c|}
\hline \multirow{2}{*}{$\begin{array}{l}\text { MARRERE GENERAL } \\
\text { HOSPITAL } \\
\text { MARRERE HEALTH } \\
\text { CENTRE }\end{array}$} & \multicolumn{3}{|l|}{2019} & \multirow[t]{2}{*}{ TOTAL } & \multirow[t]{2}{*}{$M+/-S D$} & \multicolumn{3}{|l|}{2020} & \multirow[t]{2}{*}{ TOTAL } & \multirow[t]{2}{*}{$M+/-S D$} & \multirow[t]{2}{*}{ Change } & \multirow[t]{2}{*}{$P$} \\
\hline & March & April & May & & & March & April & May & & & & \\
\hline $\begin{array}{l}\text { Total 1st ante-natal } \\
\text { visits }\end{array}$ & 158 & NDA & 200 & 358 & $165.33+/-31.64$ & 142 & 159 & 126 & 427 & $142.33+/-16.50$ & $19 \%$ & $0.327^{\star \star}$ \\
\hline $\begin{array}{l}\text { No. women with ante- } \\
\text { natal visit in } 1 \mathrm{st} \\
\text { trimester }\end{array}$ & 6 & 5 & 20 & 31 & $10.33+/-8.38$ & 7 & 6 & 10 & 23 & $7.67+/-2.08$ & $-26 \%$ & $0.658^{*}$ \\
\hline $\begin{array}{l}\text { No. women with } 4 \\
\text { ante-natal visits }\end{array}$ & 48 & 45 & 85 & 178 & $59.33+/-22.28$ & 36 & 123 & 52 & 211 & $70.33+/-46.30$ & $19 \%$ & $0.730^{\star \star}$ \\
\hline No. post-partum visits & 153 & 155 & 185 & 493 & $199.33+/-67.86$ & 371 & 5 & 187 & 563 & $108+/-40.45$ & $14 \%$ & $0.116^{\text {* }}$ \\
\hline $\begin{array}{l}\text { No. intra-hospital } \\
\text { deliveries }\end{array}$ & 135 & 111 & 142 & 388 & $156.00+/-25.12$ & 119 & 130 & 125 & 374 & $126.67+/-5.51$ & $-4 \%$ & $0.046^{*}$ \\
\hline $\begin{array}{l}\text { No. extra-hospital } \\
\text { deliveries }\end{array}$ & 4 & 7 & 8 & 19 & $6.33+/-2.08$ & 9 & 10 & 14 & 33 & $11.00+/-2.66$ & $74 \%$ & $0.074^{\star \star}$ \\
\hline No. elective C-sections & 8 & 3 & 7 & 18 & $6.67+/-1.53$ & 6 & 4 & 3 & 13 & $4.33+/-1.53$ & $-28 \%$ & $0.135^{\star \star}$ \\
\hline $\begin{array}{l}\text { Maternity - } \\
\text { Emergency room }\end{array}$ & 152 & 137 & 169 & 458 & $\begin{array}{l}152.67+/- \\
16.01\end{array}$ & 162 & 160 & 153 & 475 & $158.33+/-4.72 p$ & $4 \%$ & $0.588^{\star x}$ \\
\hline \multicolumn{13}{|c|}{ Legend: $M+/-S D$ - Mean +/- Standard deviation; NDA - No data available; $\%$ - percentage; ${ }^{*}$ - Kruskal Wallis Test; ${ }^{* *}$ - One-way ANOVA. } \\
\hline
\end{tabular}

In non-intervention area, we had an increase of $125 \%$ in the number of women with four ante-natal visits, and a decrease of $12 \%$ of the number of women with first ante-natal visit in the first trimester, all without statistical significance (see Table 2). 
Table 2

maternal health services in non-intervention area, Nampula, 2019-2020.

\begin{tabular}{|c|c|c|c|c|c|c|c|c|c|c|c|c|c|c|c|}
\hline \multirow{3}{*}{$\begin{array}{l}\text { NAMPULA } \\
\text { CENTRAL } \\
\text { HOSPITAL } \\
25 \\
\text { SEPTEMBER } \\
\text { HEALTH } \\
\text { CENTER }\end{array}$} & \multicolumn{6}{|l|}{2019} & \multirow[t]{3}{*}{ TOTAL } & \multirow{3}{*}{$\begin{array}{l}M+/-S D \\
(25 H C)\end{array}$} & \multicolumn{6}{|l|}{2020} & \multirow[t]{3}{*}{ TOTAL } \\
\hline & $\mathrm{NCH}$ & $\begin{array}{l}25 \\
\mathrm{HC}\end{array}$ & $\mathrm{NCH}$ & $\begin{array}{l}25 \\
\mathrm{HC}\end{array}$ & $\mathrm{HCN}$ & $\begin{array}{l}25 \\
\mathrm{HC}\end{array}$ & & & $\mathrm{NCH}$ & $\begin{array}{l}25 \\
\mathrm{HC}\end{array}$ & $\mathrm{NCH}$ & $\begin{array}{l}25 \\
\mathrm{HC}\end{array}$ & $\mathrm{NCH}$ & $\begin{array}{l}25 \\
\mathrm{HC}\end{array}$ & \\
\hline & Mars & & April & & May & & & & \multicolumn{2}{|l|}{ Mars } & \multicolumn{2}{|l|}{ April } & \multicolumn{2}{|l|}{ May } & \\
\hline $\begin{array}{l}\text { Total 1st } \\
\text { ante-natal } \\
\text { visits }\end{array}$ & NDA & 1910 & 21 & 1640 & NDA & 1420 & 4991 & $1656.67+/-245.43$ & 86 & 1858 & 21 & 1597 & 35 & 1186 & 4783 \\
\hline $\begin{array}{l}\text { No. women } \\
\text { with ante- } \\
\text { natal visits } \\
\text { in } 1 \text { st } \\
\text { trimester }\end{array}$ & NDA & 2804 & NDA & 2640 & NDA & 2070 & 7514 & $2504.67+/-385.26$ & NDA & 2710 & NDA & 2025 & NDA & 1858 & 6593 \\
\hline $\begin{array}{l}\text { No. women } \\
\text { with } 4 \text { ante- } \\
\text { natal visits }\end{array}$ & NDA & 203 & NDA & 180 & NDA & 247 & 630 & $210.00+/-34.04$ & NDA & 197 & NDA & 236 & NDA & 982 & 1415 \\
\hline $\begin{array}{l}\text { No. post- } \\
\text { partum } \\
\text { visits }\end{array}$ & NDA & 947 & NDA & 815 & NDA & 1033 & 2795 & $931.67+/-109.81$ & NDA & 836 & NDA & 1015 & NDA & 910 & 2761 \\
\hline $\begin{array}{l}\text { No. intra- } \\
\text { hospital } \\
\text { deliveries }\end{array}$ & NDA & 735 & NDA & 852 & NDA & 855 & 2442 & & 726 & 735 & 649 & 852 & 624 & 855 & 4441 \\
\hline $\begin{array}{l}\text { No. extra- } \\
\text { hospital } \\
\text { deliveries }\end{array}$ & NDA & NDA & NDA & NDA & NDA & NDA & 0 & & NDA & NDA & NDA & NDA & NDA & NDA & 0 \\
\hline $\begin{array}{l}\text { No. elective } \\
\text { C-section }\end{array}$ & NDA & NA & NDA & NA & NDA & NA & 0 & & 302 & NA & 268 & NA & 301 & NA & 871 \\
\hline $\begin{array}{l}\text { Maternity - } \\
\text { Emergency } \\
\text { room }\end{array}$ & NDA & 410 & NDA & 390 & NDA & 413 & 1213 & & 875 & 397 & 809 & 245 & 741 & 178 & 3245 \\
\hline
\end{tabular}

Legend: NCH - Nampula Central Hospital; $25 \mathrm{HC}$ - 25 September Health Centre; NDA - No data available; \% - percentage; ${ }^{*}$ - Kruskal Wallis Test; ${ }^{* *}$ - One-way applicable.

When Kruskal Wallis and One-Way ANOVA test are run, they show no statistical significance between both years because the p-value">a>"0.05

Concerning children and adolescent health services access indicators, quantitative data in the intervention area shows a decrease of $28 \%$ on family planning visits, $20 \%$ of vaccinated children and $18 \%$ of children completely vaccinated, all without statistical significance (see Table 3 ).

Table 3

child and adolescent health services in intervention area, Natikiri, 2019-2020.

\begin{tabular}{|c|c|c|c|c|c|c|c|c|c|c|c|c|}
\hline \multirow{2}{*}{$\begin{array}{l}\text { MARRERE HEALTH } \\
\text { CENTRE }\end{array}$} & \multicolumn{3}{|l|}{2019} & \multirow[t]{2}{*}{ TOTAL } & \multirow[t]{2}{*}{$M+/-S D$} & \multicolumn{3}{|l|}{2020} & \multirow[t]{2}{*}{ TOTAL } & \multirow[t]{2}{*}{$M+/-S D$} & \multirow[b]{2}{*}{ Change } & \multirow[b]{2}{*}{$p$} \\
\hline & March & April & May & & & March & April & May & & & & \\
\hline $\begin{array}{l}\text { Family planning } \\
\text { consultations }\end{array}$ & 175 & NDA & 276 & 451 & $164.67+/-20.21$ & 62 & 124 & 138 & 324 & $187.67+/-18.3$ & $-28 \%$ & $0.839^{* *}$ \\
\hline $\begin{array}{l}\text { No. children } \\
\text { vaccinated }\end{array}$ & 156 & 236 & 202 & 594 & $199.33+/-40.42$ & 180 & 157 & 140 & 477 & $159.00+/-20.08$ & $-20 \%$ & $0.197^{\star \star}$ \\
\hline $\begin{array}{l}\text { No. children with } \\
\text { complete vaccination }\end{array}$ & 105 & 124 & 150 & 379 & $126.33+/-22.59$ & 172 & 68 & 69 & 309 & $101.33+/-61.27$ & $-18 \%$ & $0.544^{\star \star}$ \\
\hline $\begin{array}{l}\text { Adolescents and } \\
\text { Youth Friendly Service } \\
\text { visits }\end{array}$ & NDA & NDA & NDA & 0 & & NDA & NDA & NDA & 0 & & NDA & \\
\hline Legend: $M+/-S D$ - Mea & - Stanc & d dev & tion; l & $A-N o d$ & ta available; \% - & centag & * - On & Nay $A$ & DVA. & & & \\
\hline
\end{tabular}

In non-intervention area we had a decrease of $16 \%$ in the number of children completely vaccinated and the number of adolescents and youth visits, all without statistical significance (see Table 4). 
Table 4

child and adolescent health services in non-intervention area, Nampula, 2019-2020.

\begin{tabular}{|c|c|c|c|c|c|c|c|c|c|c|c|c|c|c|c|}
\hline \multirow{2}{*}{$\begin{array}{l}\text { NAMPULA } \\
\text { CENTRAL } \\
\text { HOSPITAL } \\
25 \\
\text { SEPTEMBER } \\
\text { HEALTH } \\
\text { CENTER }\end{array}$} & \multicolumn{6}{|l|}{2019} & \multirow[t]{3}{*}{ TOTAL } & \multirow{3}{*}{$\begin{array}{l}M+/-S D \\
(25 \mathrm{HC})\end{array}$} & \multicolumn{6}{|l|}{2029} & \multirow[t]{3}{*}{ TOTAL } \\
\hline & $\mathrm{NCH}$ & $\begin{array}{l}25 \\
\mathrm{HC}\end{array}$ & $\mathrm{NCH}$ & $\begin{array}{l}25 \\
\mathrm{HC}\end{array}$ & $\mathrm{NCH}$ & $\begin{array}{l}25 \\
\mathrm{HC}\end{array}$ & & & $\mathrm{NCH}$ & $\begin{array}{l}25 \\
\mathrm{HC}\end{array}$ & $\mathrm{NCH}$ & $\begin{array}{l}25 \\
\mathrm{HC}\end{array}$ & $\mathrm{NCH}$ & $\begin{array}{l}25 \\
\mathrm{HC}\end{array}$ & \\
\hline & \multicolumn{2}{|c|}{ March } & \multicolumn{2}{|l|}{ April } & \multicolumn{2}{|l|}{ May } & & & \multicolumn{2}{|c|}{ March } & \multicolumn{2}{|l|}{ April } & \multicolumn{2}{|l|}{ May } & \\
\hline $\begin{array}{l}\text { Family } \\
\text { planning } \\
\text { Consultations }\end{array}$ & NDA & 347 & 314 & 328 & NDA & 297 & 1286 & $324.00+/-25.24$ & 401 & 315 & 314 & 293 & 234 & 389 & 1946 \\
\hline $\begin{array}{l}\text { No. children } \\
\text { vaccinated }\end{array}$ & NDA & 1593 & NDA & 1475 & NDA & 1497 & 4565 & $1521.67+/-62.75$ & 528 & 1567 & 494 & 1376 & 475 & 1538 & 5978 \\
\hline $\begin{array}{l}\text { No. children } \\
\text { with } \\
\text { complete } \\
\text { vaccination }\end{array}$ & NA & 293 & NA & 190 & NA & 193 & 676 & $225.33+/-58.62$ & NA & 219 & NA & 141 & NA & 209 & 569 \\
\hline $\begin{array}{l}\text { Adolescents } \\
\text { and Youth } \\
\text { Friendly } \\
\text { Service visits }\end{array}$ & NA & 228 & NA & 251 & NA & 221 & 700 & & NA & 189 & NA & 180 & NA & 218 & 587 \\
\hline
\end{tabular}

Legend: NCH - Nampula Central Hospital; 25 HC - 25 September Health Centre; M+/-SD - Mean +/- Standard deviation; NDA - No data available; NC- non C Not applicable; \% - percentage.

When One-Way ANOVA test is run, it shows no statistically significant difference between both years because the $p$-value" $>a>0.05$.

\section{Qualitative results}

Data saturation was attained at 19th interviews and discussed among authors. Six users (mothers and pregnant women), four TBAs from Natikiri district, three $\mathrm{MCH}$ nurses from $\mathrm{HC} 25$ Setembro, two from MHC, one from MGH and three from $\mathrm{NCH}$, were interviewed, all female with a mean age of 34 years. Transcripts were returned to HPs for their comments and there were no corrections. Records were presented to TBAs and users, as they were all illiterate, and there were no corrections.

\section{Knowledge of the Covid-19 disease}

When evaluating knowledge of the disease, we found that the basics were known by all groups. Users and TBAs were able to mention at least three major symptoms such as cough, fever and difficulty breathing.

"...it's a flu, in which the person has a cough, headache, neck pain, feels cold and has fever." (TBA, Natikiri, 37 years).

They were also able to mention simple preventive methods, such as washing hands, social distancing, and wearing masks whenever in public.

“... we have to wash our hands with water and soap or ashes" (Post-partum women, Natikiri, 32 years).

"... we have to use masks, whenever we go out!" (Pregnant women, Natikiri, 25 years).

As expected, HP had more knowledge on the origin of the disease,

"CoVid-19 is a contagious disease originated in China and is caused by a new coronavirus SARS-cov-2" (MCH Nurse, MHC, 24 years).

Also, on symptoms, and prevention methods:

"... if the person travels to a country contaminated by CoVid-19 they have to be quarantined for 14 day" (MCH Nurse, 25 September HC, 28 years).

“...everyone needs to use masks and maintain social distancing of 1.5m." (MCH Nurse, NCH, 32 years).

\section{Impact of CoVid-19 in access to health units}

During interviews, all groups stated that they anecdotally saw the number of people frequenting the HUs decreased significantly, due to the fear of contamination in the $\mathrm{HU}$. 
The TBAs related that there was a reduction in the number of patients seen in the community. Also, both users and TBAs, mentioned that due to the CoVid-19 pandemic, important tasks such as going preaching their religion in churches and mosques was prohibited. Adolescents' traditional initiation rites were also conditioned, as they are considered activities of populational agglomeration. Work overall was affected, as they were forced to stay home, farming was reduced to intermediate days or ceased completely. Additionally, TBAs referred a decrease in the number of community members who visited them. They mentioned that they also respected and enforced prevention measures, on the few community members who visited them.

"The number of health professionals has decreased, and they leave early, so the waiting time has increased a bit" (TBA, Natikiri, 28 years).

HPs recognise a much lower workload but also a reduction in MCH HPs number and work hours, so as a population behaviour change in terms of personal hygiene.

"The flux of patients is reduced; it may be because they fear coming to the hospital thinking that they might be contaminated here in the Nampula Central Hospital" (MHC Nurse, NCH, 36 years).

"...in the wards there is only one nurse per shift, and because of the pandemic if one gets sick, we will be forced to work every day to cover her!" (MHC Nurse, $\mathrm{MGH}, 26$ years).

Interviews with patients show they recognise population' behaviour change to prevent the infection, and in reducing access to health services.

\section{Health system response}

The lack of HPs in HUs was unanimous for the three levels (MHC and Health Centre 25 de Setembro - level 1, MGH - level 3 and NCH - level 4). This is a recurrent complaint from HPs, TBAs and patients.

HPs keep educating users about CoVid-19 prevention methods, and the necessary conditions for consultations.

“...community awareness speeches about prevention methods continue." (MHC Nurse, MHC, 26 years).

"... we reinforce measures and make the community understand, to comply to the measures of prevention of this disease." (MGH Nurse, NCH, 36 years).

"the health professionals refuse to treat patients with no masks and that didn't wash their hands" (MCH Nurse, NCH, 34 years).

Users and TBAs mentioned that they continue to frequent the healthcare services, mostly to vaccinate their children, because the vaccines are no longer available in the communities, forcing parents to go to the $\mathrm{HU}$ to get the child vaccinated (mobile brigades have not been going to the communities to deliver the vaccines).

"...these vaccines have not come to the community, so the mothers have to go to the hospital!" (Post-partum women, Natikiri, 22 years).

\section{Impact on motorcycle-ambulance usage}

With regards to the usage of motorcycle ambulances, a delivering women and emergencies transportation system implemented by ACPH project in Natikiri, the nurses in $\mathrm{MHC}$ and $\mathrm{MGH}$ were not able to provide any satisfactory answers (they had no information of this intervention). The users and TBAs mentioned that the motorcycle ambulances continued to circulate normally in some areas and in others reduced.

“...the motorcycle ambulances have reduced their circulation because of the disease!" (TBA, Natikiri, 28 years).

\section{Discussion}

Primary and secondary health care services assessment on a pandemic, is an effort to attain global health towards universal health cover. We assessed the two systems, where primary care should be a strong leader. Government's Covid-19 pandemic preventive measures might have reduced the case number in Mozambique, but they have reduced maternal, children and adolescent's health services access in Nampula. These facts are recognised globally. ${ }^{10}$ It is also known that countries' primary care systems strength, does not influence the pandemic mortality rate, which is more dependant of perceived stringent border control, movement restriction, and testing regimes. ${ }^{11}$

Behaviour change promoted by the government on preventive activities, targeting community health workers, TBAs, traditional leaders and healers with trainings, ${ }^{12}$ and general population with a media campaign through television and radio, launched in May 2020, has attained most population, concerning Covid-19, but reduced users and HP' MCH preventive attitudes and behaviours, within the public health system, in primary and secondary health care services. This might be an opportunity to MISAU to reformulate its population information and education strategy. ${ }^{13}$

The health information system is deficient like in other countries in Africa, ${ }^{14}$ and restrained conclusions. A quaternary hospital has poor quality records and a tertiary hospital incorporates a primary health care centre' indicators.

The number of pregnant women with four ante-natal visits increased, but we consider this result independent of Covid-19 impact, since the three previous visits have occurred before the state of emergency.

Page $7 / 10$ 
Comparing the city centre HUs with sub-urban Natikiri, with a more rural and illiterate population, we verify a slight positive impact of ACPH project in maternal health (number of women in first ante natal visit, women with four ante-natal visits, post-delivery visits, increasing faster than the demographic increase rate of $2.8 \%),{ }^{15}$ without results in children (reduction in the number of vaccinated children and children completely vaccinated) and adolescent's health at Adolescent and Youth Friendly Service (AYFS) visits. Those results show some ACPH outputs sustainability, based on population empowerment in health issues. This shows that Natikiri and Mozambican national public health education interventions, need to target better preventive behaviours for children and adolescents, supported by family friendly health services, namely in maternity deliveries, vaccination and contraception. ${ }^{16}$ Contraception is an essential need for adolescents and young adult patients, and new approaches should be developed to provide this crucial care.

Study limitations: MISAU' programs statistical data is not currently available in several HU and there are several data collecting issues, limiting our analysis and conclusions. Telephone interviews due to emergency state' social distancing, had some constraint with users and limited language (corporal) communication.

\section{Conclusions}

Our results demonstrate negative collateral effects of Covid-19 pandemic on $\mathrm{MCH}$ in Nampula, reducing the number of maternity deliveries and increasing domiciliary births.

ACPH project, empowered local population on SRH, reducing moderately these effects, but had no impact on child and adolescent health. This shows the need to better the health information and education system in Mozambique, targeting preventive interventions with children and youth, namely on family planning.

MISAU, although developing a media campaign to promote population access to preventive services and chronic diseases consultations, is not attaining the general population, with low Portuguese language capacity, and away from media (TV, radio).

This will require investing in effective communication with urban and rural populations, designing an innovative media campaign, in local languages, through community health workers, and implementing an HPs training program on communication and values.

The Alert Community project has implemented community-based interventions to improve community' understanding of $\mathrm{SRH}$, and further research will assess long lasting effect on reducing the negative collateral effects of Covid-19 pandemic in Natikiri.

\section{Abbreviations}

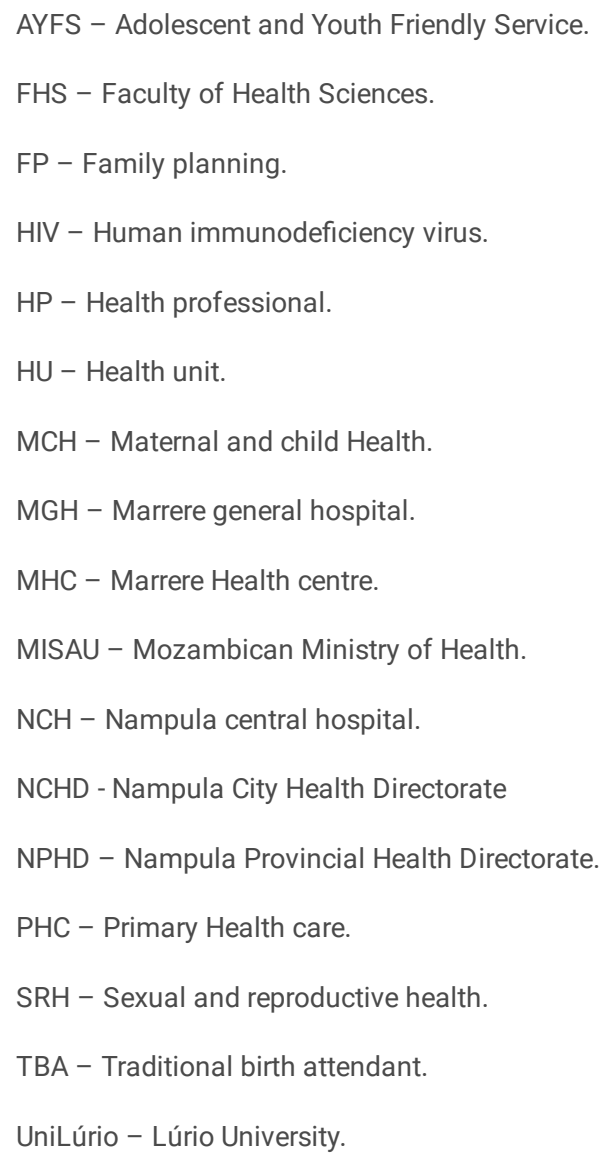

\section{Declarations}


This research was allowed by the Faculty of Health Sciences of Lúrio University, Nampula Provincial Health Directorate, Nampula City Health Directorate, and approved by Lúrio University Bioethics Health Committee (02/CBISUL/16), and the University of Saskatchewan Bioethics Committee (15-112). We followed all Helsinki Declaration (2013) recommendations, all participants were volunteers, anonymity guaranteed, free to desist if uncomfortable without any negative condition, recording an informed declaration term. This research had no risk or remuneration to participants. They agreed to give their time and opinion on this topic to benefit the population, contribute to improve public health policy interventions and implementation research, and empower inhabitants with SRH knowledge. The study did not involve the use of animals.

\section{Consent for publication}

This manuscript does not contain data from any individual person. Not applicable.

The authors declare they have reviewed this manuscript and agree to submit it to BioMed Central Health Services Research Journal. The Faculty of Health Sciences at Lúrio University has authorised this publication.

\section{Availability of data and materials}

The datasets used and analysed during the current study are available from the corresponding author on reasonable request.

\section{Competing interests}

The authors declare they have no competing interests with study design or final report, no financial or personal relationships with other people or organizations that could inappropriately influence this research.

\section{Funding}

The study was funded by Lúrio University Faculty of Health Sciences. The funding body had no role in the design of the study and collection, analysis, and interpretation of data in writing the manuscript.

\section{Authors contributions}

PP: Study protocol conception and design, data analysis and interpretation, article draft, final approval of the version to be published.

CM: Study protocol design, data collection and interpretation, article draft, final approval of the version to be published.

AA: Study protocol design, data collection and interpretation, article draft, final approval of the version to be published.

JM: Study protocol design, data interpretation, article draft, final approval of the version to be published.

MM: Study design, data treatment, analysis and interpretation, final approval of the version to be published.

RS: Study protocol conception and design, data interpretation, article draft, final approval of the version to be published.

CB: Study protocol conception and design, data interpretation, final approval of the version to be published.

\section{Acknowledgements}

Dr. António Falamique, Asimbawe Kiza and members of the Lúrio University Health Research Students Board.

\section{References}

1. 360 GRN Revolution. Covid-19, Actualização. Worldometer. 28 Agosto 2020.

2. WHO. Pulse survey on continuity of essential health services during the Covid-19 pandemic. Interim report. World Health Organization. Geneva. 27 August 2020.

3. Melo R, Tavares N, Duarte R. Covid-19 and the invisible damage. Acta Med Port 2020 xxx;33(AOP):xxx-xxx - https://doi.org/10.20344/amp.13911.

4. Poudel A. A 200 percent increase in maternal mortality since the lockdown began. The Kathmandu. May 27, 2020.

5. Kringos D, Carinci F, Barbazza E, et al. Managing COVID-19 within and across health systems: why we need performance intelligence to coordinate a global response. Kringos et al. Health Research Policy and Systems (2020) 18:80. https://doi.org/10.1186/s12961-020-00593-x.

6. Coronini-Cronberg S, Maile E, Majeed A. Health inequalities: the hidden cost of COVID-19 in NHS hospital trusts? Journal of the Royal Society of Medicine; 2020, Vol. 113(5) 179-184. DOI: 10.1177/0141076820925230

7. Shepherd J, Friedland G. Preventing Covid-19 collateral damage. Downloaded from https://academic.oup.com/cid/advance-articleabstract/doi/10.1093/cid/ciaa772/5858267 by guest on 18 June 2020.

8. Belo C, Pires P, Josaphat J, et al. Maternal and new-born mortality: community opinions on why pregnant women and new-borns are dying in Natikiri, Mozambique. International Journal of Research, Volume 04 Issue 6 May 2017. p-ISSN: 2348 - 6848. e-IAAN: 2348-795x.

http://edupediapublications.org/journals/ 
9. Pires P, Siemens R, Mupueleque M. Improving sexual and reproductive health and practice in Mozambican families with media campaign and volunteer Family Health Champions. Fam Med Com Health 2019;7:e000089. Doi: 10.1136/fmch-2018-000089.

10. Roberton T, Carter E, Chou V, et al. Early estimates of the indirect effects of the COVID-19 pandemic on maternal and child mortality in low-income and middle-income countries: a modelling study. Lancet Glob Health 2020. Published Online May 12, 2020. https://doi.org/10.1016/S2214-109X(20)30229-1

11. Goodyear-Smith F, Kinder K, Mannie C, et al. Relationship between the perceived strenght of countries' primary care system and COVID-19 mortality: na International survey study. BJGP Open 2020; DOI: 10.3399/bjgpopen20X101129

12. MISAU. Formação para Actores Comunitários sobre Covid-19. Ministério da Saúde. República de Moçambique. Maputo. 30 Abril 2020.

13. Kennedy D. Support for school-aged-moms in Jamaica during Covid-19. Education Plus Development. Brookings. 2020.

14. Munkwa P. Implications of Covid-19 on workplace: OSH context. AUDA-NEPAD. International Labour Organisation. 25 May 2020.

15. INE. Resultados Definitivos Censo 2017: IV Recenseamento Geral da População e Habitação. Instituto Nacional de Estatística. Maputo.2019. www.ine.gov.mz

16. Wilkinson T, Kottke M, Berlan E. Providing contraception for young people during a pandemic is essential Health care. JAMA Paediatrics Published online May 7, 2020. Downloaded From: https://jamanetwork.com/ by Paulo Pires on 05/07/2020.

\section{Supplementary Files}

This is a list of supplementary files associated with this preprint. Click to download.

- CovidCOREQChecklist.docx 